\title{
Pelatihan Bisnis dengan Digital Marketing ntuk Generasi Muda di Kota Surakarta
}

\author{
Dewi Kartikasari ${ }^{1)}$, Kurniawati Darmaningrum ${ }^{2)}$, Zandra Dwanita Widodo ${ }^{3)}$, Septylyta Rahmita \\ Putri ${ }^{4)}$, Nurita Elfani Prasteyaningrum ${ }^{5)}$, Agus Purwanto6)
}

\begin{abstract}
1) STIE St Pignatelli Surakarta (Program Studi Akuntansi,Fakultas Ekonomi \& Bisnis Surakarta, Indonesia) 2), 3), 6) Universitas Tunas Pembangunan Surakarta (Program Studi Manajemen, Fakultas Ekonomi \& Bisnis, Surakarta, Indonesia)

4) Universitas Kusuma Sahid Surakarta (Program Studi Perdagangan Internasional Fakultas Ekonomi dan Bisnis, Surakarta Indonesia) ${ }^{5}$ Universitas Surakarta (Program Studi Akuntansi, Fakultas Ekonomi \& Binsis Surakarta, Indonesia)
\end{abstract}

E-mail : ribkadewikartikasari@gmail.com

\begin{abstract}
ABSTRAK
Pemasaran merupakan elemen yang penting dalam menjalankan bisnis, sehingga dalam awal perencanaan bisnis diperlukan waktu untuk memikirkan metode pemasaran apa yang benar sehingga barang atau jasa yang dijual laku di pasar. Hal ini dikarenakan perencanaan bisnis diawal akan mempengaruhi keberhasilan bisnis, termasuk metode/cara pemasaran apa dan bagaimana caranya dilakukan oleh para pelaku usaha. Masalah utama yang dihadapi oleh generasi muda dalam memulai bisnis adalah kurangnya pengetahuan dalam membangun sebuah bisnis yang memiliki prospek yang baik, dan juga kurangnya pengetahuan tentang pemasaran digital, khususnya media sosial dan ecommerce. Kurangnya pengetahuan ini tentang pemasaran digital telah menginspirasi tim pengabdian masyarakat untuk memberikan sosialisasi dan memberikan pelatihan tentang penggunaan ini teknologi informasi dan komunikasi. Jika generasi muda mengerti pentingnya pemasaran digital untuk peluang bisnis, mereka adalah diharapkan dapat termotivasi untuk menggunakan digital marketing sebagai sarana komunikasi untuk membuka peluang bisnis mereka, dan dapat mempraktekannya secara langsung dengan memanfaatkan media sosial dan e-commerce. Berdasarkan masalah utama mitra yaitu kurangnya informasi manajemen pemasaran, solusi yang ditawarkan kepada mitra adalah dengan memberikan materi terkait pemasaran digital untuk meningkatkan pendapatan. Metode yang digunakan adalah ceramah, tanya jawab, dan simulasi. Target yang ingin dicapai dalam kegiatan pengabdian kepada masyarakat merupakan implementasi dari pengenalan digital marketing pada generasi muda dalam upaya memotivasi dan meningkatkan semangat kewirausahaan untuk generasi muda.
\end{abstract}

Kata kunci: Pemasaran digital, generasi muda, sosial media, e-commerce

\begin{abstract}
Marketing is an important element in running a business, so that in business planning it takes time to plan marketing methods that can help to sell the goods or services in the market. This is because the initial business planning will affect the success of the business, including what marketing methods/methods are and how it is done by the business. The main problem faced by the younger generation in starting a business is the lack of knowledge in building a business that has good prospects, and also the lack of knowledge about digital marketing, especially social media and e-commerce. The lack of knowledge about digital marketing has inspired the community service team to provide socialization and provide information about the use of this technology and communication. If the younger generation understands the importance of digital marketing for business opportunities, they are expected to be able to use digital marketing as a means of communication to open their business opportunities, and can practice it directly by utilizing social media and e-commerce. Based on the partner's main problem, namely the lack of marketing management information, the solution offered to partners is to provide materials related to digital marketing to increase revenue. The method used is lecture, question and answer, and simulation. The target to be achieved in community service is the implementation of the introduction of digital marketing to the younger generation in an effort to motivate and increase the entrepreneurial spirit for the younger generation.
\end{abstract}

Keywords: Digital marketing, young generation, social media, e-commerce.

PENDAHULUAN

Jurnal Pengabdian Masyarakat Tunas Membangun
Perkembangan teknologi saat ini berkembang dengan pesat, sehingga kemampuan sebuah 
negara dalam mengadopsi teknologi digital sangat menentukan perkembangan ekonomi serta posisi negara dalam rantai penciptaan nilai global atau global value chain. "Kemampuan mengkreasi dan juga mengadopsi teknologi digital sangat menentukan bagaimana sebuah perekonomian dan negara mampu untuk masuk di dalam sistem global value chain yang akan meningkatkan produktivitas," kata Menteri Keuangan, Sri Mulyani dalam Keynote Speech yang disampaikan secara virtual dalam Rapat Koordinasi Keuangan Kementerian Komunikasi dan Informatika Tahun 2021.

Perkembangan revolusi industri ke-4 telah membuat semua negara berlomba-lomba untuk bisa memiliki kemampuan dalam meningkatkan produktivitas dengan menggunakan teknologi digital. Indonesia memiliki kesempatan untuk turut serta dalam kompetisi ini namun ia juga mengingatkan banyak tantangan yang harus dihadapi. Salah satu tantangan yang ia kemukakan adalah masih rendahnya jumlah pengguna aktif internet yang memanfaatkan internet untuk transaksi perdagangan.

Penggunaan platform digital di Indonesia masih terbatas atau lebih banyak digunakan untuk berkomunikasi di media sosial namun untuk fasilitas produktif seperti e-commerce baru $3 \%$. Angka tersebut sangat jauh jika dibandingkan dengan jumlah pengguna aktif internet yang menggunakan internet sebagai media berkomunikasi yaitu sebesar 36 persen dan 21 persennya menggunakan internet untuk mengakses media sosial.

Meskipun demikian, jumlah transaksi ecommerce telah berkembang sangat pesat selama beberapa tahun terakhir bahkan mampu melahirkan berbagai perusahaan unicorn yang telah diakui baik di regional maupun internasional. Menteri Sri Mulyani menyatakan tantangan lain yang dihadapi adalah masih rendahnya kepercayaan masyarakat terhadap sistem pembayaran digital dan belum meratanya akses internet di Indonesia.

Di tengah segala keterbatasan, Menkeu mengatakan ekonomi digital di Indonesia telah mencapai pertumbuhan $49 \%$ per tahun dan pertumbuhan e-commerce di Indonesia bahkan diprediksi akan melampaui 130 miliar USD pada tahun 2025. Pandemi Covid-19 telah mendorong semua kegiatan dilakukan dengan memanfaatkan teknologi digital. Penggunaan teknologi informasi dan komunikasi atau bahkan transformasi ke digitalisasi menjadi sebuah keharusan dan bahkan telah dipaksa dengan kondisi akibat pandemi yang tidak memberikan pilihan namun memaksa untuk harus masuk kepada platform digital.
Hal ini, menurut dibuktikan dengan tumbuhnya sektor teknologi informasi dan komunikasi sebesar $10,6 \%$ di tengah kontraksi ekonomi Indonesia sebesar $2 \%$. Pembangunan infrastruktur digital adalah hal penting yang harus terus dilakukan demi mewujudkan visi Indonesia untuk menjadi pemain digital dunia.

Digital marketing memberikan kesempatan untuk pembeli agar dapat memperoleh seluruh informasi mengenai produk dan bertransaksi melalui internet, dan memungkinkan penjual memantau dan menyediakan kebutuhan serta keinginan calon pembeli tanpa batasan waktu dan geografis. Media promosi digital diharapkan menjadi pilihan yang efektif untuk pelaku usaha dalam mengembangkan bisnis dan menjangkau pasar nasional maupun internasional. Media promosi konvensional yang banyak membutuhkan biaya dan jauh lebih rumit dengan sendirinya tidak lagi menjadi perhatian utama bagi pelaku pelaku usaha karena adanya digital marketing. Pelaku usaha, dengan menggunakan e-commerce atau marketplace dapat menjangkau calon konsumen yang lebih luas dan lebih banyak, tidak hanya terbatas pada suatu wilayah promosi saja. Digital marketing dan ecommerce commerce atau marketplace dapat menjangkau wilayah yang lebih luas dibanding pemasaran secara konvensional, sehingga hal ini menjadi pilihan yang solutif untuk ekspansi bisnis.

Pemasaran dengan sosial media dan ecommerce saat ini sedang meningkat pesat dikarenakan pandemi yang membuat sulitnya peluang untuk berjualan secara offline. Digital marketing menjadi alternatif yang bisa digunakan pelaku usaha untuk memasarkan produk mereka, membuka peluang baru, serta meningkatkan penjualan. Pengetahuan tentang digital marketing tidak hanya mengenai pembelian dan penjualan produk saja, tetapi juga mencakup promosi dan pemasaran produk yang lebih luas.

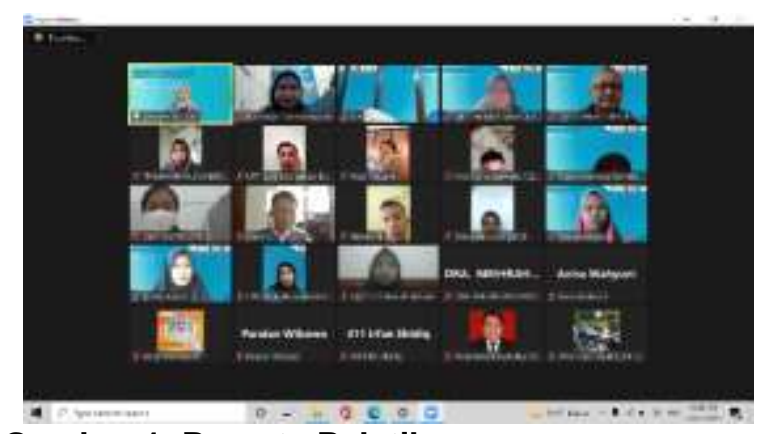

Gambar 1. Peserta Pelatihan 


\section{Pemasaran Digital}

Pemasaran digital merupakan pemasaran yang dimana pesan dikirim menggunakan media yang tergantung pada transmisi digital. Namun sejauh ini, internet merupakan media digital paling signifikan. (Bird, 2007). Banyak ahli yang mengemukakan bahwa terjadi perubahan dalam pemasaran yang disebabkan karena perkembangan teknologi, terutama internet. Keuntungan dari digital marketing menggunakan internet adalah lebih mudah, lebih murah atau lebih cepat untuk berkomunikasi. (Ryan \& Jones, 2009 ; Bird, 2007 ; Chaffey dan Smith, 2002).

Namun pemasaran digital bukan hanya tentang memahami teknologi yang digunakan, melainkan tentang memahami orang, bagaimana mereka menggunakan teknologi itu, dan bagaimana memanfaatkan teknologi untuk terlibat dengan mereka secara lebih efektif, dan harus lebih didorong oleh kualitas komunikasi daripada kuantitasnya (Taiminen \& Karjaluoto, 2014 ; Ryan \& Jones, 2009 ; Rowan, 2002).

Dimensi dari digital marketing adalah website, optimasi mesin pencari, periklanan berbasis klik pencarian berbayar, pemasaran afiliasi dan kemitraan, hubungan masyarakat online, jejaring sosial, email, manajemen hubungan konsumen (Ryan \& Jones, 2009). Media sosial juga merupakan media yang sangat potensial dan paling efektif dalam pemasaran digital untuk berbicara dengan pelanggan. (Weber, 2009).

Hasil yang ingin dicapai melalui pemasaran digital memerlukan banyak upaya Pemasar harus memiliki strategi bisnis dalam pemasaran digital (Yasmin, et.al, 2015 ; Gibson, 2018). Yasmin et.al (2015) juga mengemukakan bahwa dalam pemasaran digital diperlukan upaya, percobaan dan kesalahan. Kata kuncinya adalah "uji, pelajari, dan kembangkan". Hal tersebut merupakan inti dari semua inisiatif pemasaran digital.

Digital marketing dapat membangun brand awareness, yang dilakukan dengan cara menentukan media sosial yang akan digunakan, perencanaan pesan, dan menentukan teknik bauran promosi yang akan digunakan. (Oktaviyani dan Rustandi, 2018) Beberapa upaya telah dilakukan untuk meningkatkan keterampilan pemasar dalam digital marketing.

Pelatihan untuk meningkatkan keterampilan dan pengetahuan pemasar telah memiliki efek positif. Melalui workshop digital marketing (penyampaian materi, diskusi dan praktik) maka diharapkan pemasar lebih memahami pentingnya penggunaan media internet untuk meningkatkan daya saing usahanya
(Widyaningrum dan Bharata, 2017 ; Baladraf dkk, 2018 ). Beberapa pelatihan yang dapat dilakukan seperti alih pengetahuan dan teknologi dalam perancangan bisnis online, pemanfaatan E-Commerce yang sudah ada, pemanfaatan transaksi perbankan secara online, penggunaan Social Media dan Search Engine Optimization (SEO) dalam penjualan dan pemasaran secara online. (djamaludin dkk, 2016)

\section{METODE}

Metode yang digunakan dalam pengabdian masyarakat kali ini adalah ceramah, tanya jawab, dan simulasi. Target yang ingin dicapai dalam kegiatan pengabdian kepada masyarakat merupakan implementasi dari pengenalan digital marketing pada generasi muda dalam upaya memotivasi dan meningkatkan semangat kewirausahaan untuk generasi muda.

Peserta pelatihan merupakan anak-anak muda yang memiliki usaha maupun berniat memiliki usaha di Kota Surakarta dengan menggunakan aplikasi Zoom Meeting. Salah satu alasan pertimbangan pemilihan penggunakan aplikasi adalah kemudahan akses bagi peserta pelatihan dan pertimbangan tentang social distancing untuk menghindari kluster baru Covic-19. Metode ceramah dipilih untuk memberikan materi yang disampaikan, kemudia disambung dengan tanya jawab dan praktek. Pelatihan digital marketing ini akan diselenggarakan dengan tahapan-tahapan sebagai berikut :

1. Pengenalan digital marketing

2. Pengetahuan dan teknologi dalam perancangan bisnis online.

3. Pelatihan penggunaan sosial media dan ecommerce.

4. Pemanfaatan E-Commerce

5. Pemanfaatan transaksi perbankan secara online

6. Penggunaan Social Media dan Search Engine Optimization (SEO) dalam penjualan dan pemasaran secara online.

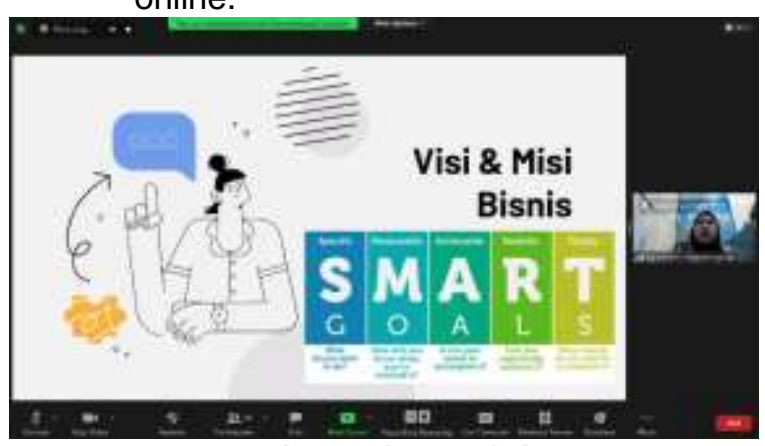

Gambar 2. Materi Pelatihan Digital

Marketing 


\section{HASIL DAN PEMBAHASAN}

Hasil pelaksanaan kegiatan secara garis besar terdiri dari ketercapaian target jumlah peserta, ketercapaian tujuan kegiatan, serta ketercapaian target materi yang telah direncanakan. Pelatihan ini diharapkan mampu membantu mereka memahami dam mempersiapkan diri dan usahanya agar sukses dalam menggunakan pemasaran digital dan e-commerce.

Berdasar hasil wawancara dengan mitra dari pelatihan ini yaitu generasi muda di Kota Surakarta yang memiliki atau berencana memiliki usaha, permasalahan yang dimiliki oleh pelaku adalah kurangnya pengetahauan tentang digital marketing, penggunaan sosial media dan e-commerce, dan cara pembuatan konten pemasaran yang menarik bagi konsumen. Oleh karena itu, pelatihan ini dibuat dengan tahap-tahap sebagai berikut: pengenalan digital marketing, pengetahuan dan teknologi dalam perancangan bisnis online, pemanfaatan E-Commerce yang sudah ada, pemanfaatan transaksi perbankan secara online, penggunaan Social Media dan Search Engine Optimization (SEO) dalam penjualan dan pemasaran secara online. Setelah dilakukan pelaksanaan kegiatan pengabdian masyarkat ini, dirasakan perlu dilakukan kegiatan pendampingan dan pemberian motivasi kepada pelaku usaha secara terus menerus agar manfaat dari pelatihan ini dapat dirasakan oleh pelaku usaha.

Ketercapaian target materi pada kegiatan pengabdian masyarakat ini cukup baik karena materi yang disampaikan sudah disesuaikan dengan kondisi lapangan tempat diadakannya pengabdian masyarakat ini. Selain itu materi disampaikan dengan sistem tanya jawab dan diskusi sehingga peserta juga dapat memberikan pertanyaan maupun berbagi pengalaman. Keterlibatan ini penting bagi jalannya pengabdian masyarakat agar dapat dipastikan bahwa materi yang diberikan dapat tersampakan maksud dan tujuannya.

\section{DAFTAR RUJUKAN}

Baladraf, M.I.F., Sembodo, G., Hasanah, L.U \& Pramono. A. (2018). Pelatihan Sukses Berbisnis Online Memajukan Perekonomian

Masyarakat Melalui Pemasaran Online Putat Jaya Surabaya. Jurnal Abdikarya : Jurnal

Pengabdian Dosen dan Mahasiswa, Februari 2018 Vol 01 No 1
Bird, D. (2007). Commonsense Direct \& Digital Marketing. London : Kogan Page.

Chaffey, D \& Smith, P.R (2008). e-Marketing Excellence : Planning and optimizing your digital marketing. USA : Elsevier.

Djamaludin., Aviasti., Rukmana, A.N \& Rukmana, O. (2016) Peningkatan Kemampuan Usaha Kecil Menengah di Wilayah Bandung Raya dalam Pemanfaatan

Internet Sebagai Sarana Pemasaran dan Perluasan Jangkauan Pasar. Ethos (Jurnal Penelitian dan Pengabdian Masyarakat). Vol 4, No.1, Januari 2016

Gibson, C. (2018). The Most Effective Digital Marketing Strategies \& Approaches : A Review of Literature. International Journal of Scientific and Research Publications, Volume 8, Issue 2, February 2018.

Oktafiyani, F \& Rustandi, D (2018). Digital Marketing dalam Membangun Brand Awareness. PRofesi Humas, Volume 3, No. 1, 2018, hlm. 1-20

Rowan, W. (2002) Digital Marketing : Using New Technologies to Get Closer to Your Customers. London : Kogan Page

Ryan, D \& Jones, C (2009) Understanding Digital Marketing : Marketing strategies for engaging the digital generation. London : Kogan Page

Taiminen, H.M \& Karjaluoto, H (2014). The usage of digital marketing channels in SMEs. Journal of Small Business and Enterprise Development Vol. 22 No. 4, 2015 pp. 633-651

Widyaningrum, P.W \& Bharata, W (2017). Workshop Internet Dan Digital Marketing Untuk Meningkatkan Daya Saing Pada Kelompok Pengusaha Muda Ponorogo. Jurnal pengabdian kepada masyarakat ADIMAS vol.1 no. 1.Maret.Tahun 2017.

Weber. L (2009) Marketing to The Social Web : How Digital Customer Communities Build Your Business. Canada : John Wiley \& Sons, Inc.

Yasmin, A., Tasneem, S \& Fatema, K (2015). Effectiveness of Digital Marketing in the Challenging Age: An Empirical Study. International Journal of Management Science and Business Administration. Volume 1, Issue 5, April 2015, Pages 6980 